\title{
Inhibition of syndecan-1 expression and function in oral cancer cells
}

\author{
TAKASHI MURAMATSU ${ }^{1}$, MASATO SAITOH ${ }^{2}$, YASUFUMI RO ${ }^{1,3}$, \\ TOMOKO UEKUSA ${ }^{1}$, ERI IWAMURA ${ }^{1}$, KAZUMASA OHTA ${ }^{4}$, \\ YOHKO KOHNO $^{5}$, YOSHIHIRO ABIKO ${ }^{2}$ and MASAKI SHIMONO ${ }^{1}$
}

\author{
${ }^{1}$ Department of Pathology, Tokyo Dental College, Chiba; ${ }^{2}$ Department of Dental Science, Institute of Personalized \\ Medical Science, Health Sciences University of Hokkaido, Sapporo; ${ }^{3}$ Departments of Oral and \\ Maxillofacial Surgery; Tokyo Dental College, Chiba; ${ }^{4}$ Department of Biology, Tokyo Medical University, \\ Tokyo; ${ }^{5}$ Department of Oral Pathology, Showa University, School of Dentistry, Tokyo, Japan
}

Received April 16, 2008; Accepted July 31, 2008

\section{DOI: $10.3892 /$ or_00000151}

\begin{abstract}
Syndecan-1 has been shown to be a prognostic factor in various types of tumors, suggesting its correlation with malignancy and metastasis. In the present study, we examined the expression of syndecan- 1 in oral cancer cell lines and tested whether transfection of an siRNA against human syndecan-1 affected the malignant potential of these cells. Seven different human oral cancer cell lines (HSC2, HSC3, HSC4, Ca9-22, $\mathrm{SAS}, \mathrm{KB}$ and BSC-OF) were used. To evaluate the mRNA expression of syndecan-1 in these cell lines, quantitative realtime RT-PCR (QRT-PCR) was carried out. In order to examine syndecan-1 function, siRNA was transfected into the cells, after which the cell growth rate and invasive ability were evaluated. As a negative control, a random sequence siRNA was used. QRT-PCR showed that syndecan-1 was expressed in Ca9-22 cells and that it was significantly higher ( $>10$-fold) than in the other oral cancer cell lines. Transfection of syndecan-1 siRNA was carried out on Ca9-22 cells, which increased their growth rate 1.4-fold above controls. The invasive ability of Ca9-22 cells treated with syndecan-1 siRNA was significantly higher (2-fold; $n=5$ ) than the controls. These results suggest that Ca9-22 oral cancer cells are a useful model to study syndecan-1 function and they show that syndecan-1 directly contributes to the growth and invasive ability of these cells.
\end{abstract}

\section{Introduction}

Oral cancer is the fifth most common type of cancer in the world. Despite modern intervention, the 5-year survival rate for this disease has improved only marginally over the past

Correspondence to: Dr Takashi Muramatsu, Tokyo Dental College, Department of Pathology, 1-2-2, Masago, Mihama-ku, Chiba 261-8502, Japan

E-mail: tmuramat@tdc.ac.jp

Key words: oral cancer, invasion, syndecan-1, squamous cell carcinoma decade (1) and recurrent disease is observed in $50 \%$ of patients $(2,3)$. Survival curves of oral cancer patients have plateaued over the past 2 decades and remain among the worst of all cancer sites. Therefore, recent studies in this field have focused on the development of biomarkers for early detection, disease monitoring and determining the prognosis of patients with oral cancer $(4,5)$.

Cell surface adhesion receptors bind cells to the extracellular matrix (ECM) and couple such interactions with intercellular signaling mechanisms (6). It is apparent that alterations in cell adhesion can influence almost every stage of cellular transformation. The development of malignant epithelial neoplasms is associated with the disruption of cellto-cell and cell-to-matrix adhesion $(7,8)$. Syndecans are a family of heparan sulphate proteoglycan receptors that participate both in cell-to-cell and in cell-to-matrix adhesion (9). The syndecan family is composed of four closely related proteins (syndecans-1 to 4) which are encoded by four different genes (9). Syndecan-1 binds cells via its heparan sulphate chains to a variety of components of the interstitial matrix, including types I, III and V collagen, fibrillar collagen (10), fibronectin (11) and tenascin (11). Earlier studies noted that syndecan-1 levels correlate with malignancy in various tissues including the uterine cervix $(12,13)$ and the esophagus (14). Studies on syndecan-1 expression in head and neck carcinomas have suggested that reduced expression of syndecan-1 is associated with the prognosis of these neoplasms $(15,16)$. Ro et al $(17)$ reported that a reduction of syndecan-1 expression correlated with tumor size and invasion in squamous cell carcinomas of the tongue. However, expression levels and function(s) of syndecan- 1 in oral cancers remain unknown. In the present study, we examined syndecan-1 expression in a number of oral cancer cell lines and used the siRNA approach to characterize the function(s) of syndecan-1 in these cells.

\section{Materials and methods}

Cell cultures. Human oral squamous cell carcinoma (SCC) cell lines, HSC2, HSC3, HSC4, SAS and KB, were obtained from 
Table I. Sequences of primers used in this study.

Syndecan-1

the Japanese Cancer Research Resources Bank (JCRB). BSC-OF was established from an oral basaloid squamous cell carcinoma by Abiko et al (18). All cell lines were grown in Dulbecco's modified Eagle medium (DMEM) or in DMEM/ F-12 (Invitrogen, Grand Island, NY, USA) containing 10\% fetal bovine serum (Sigma-Aldrich, St. Louis, MO, USA) and penicillin-streptomycin $\left(100 \mathrm{U} / \mathrm{ml}\right.$, Invitrogen) at $37^{\circ} \mathrm{C}$ in a humidified incubator containing $5 \% \mathrm{CO}_{2}$.

RNA isolation and quantitative real-time RT-PCR (QRT-PCR). Total RNA was extracted using the acid guanidiniumthiocyanate-phenol-chloroform (AGPC) method with TRIzol (Invitrogen) and cDNA synthesis was performed as described in our previous study (19). QRT-PCR was carried out using SYBR-Green and AmpliTaq Gold DNA polymerase (PE Applied Biosystems, Foster City, CA, USA) according to our previous study (19). Primers for human syndecan-1 and glyceraldehyde-3-phosphate dehydrogenase (GAPDH) were used; the sequences of the primers are shown in Table I. Amplification was then performed in duplicate using the primer sets in an ABI PRISM 7700 Sequence Detector (PE Applied Biosystems) with denaturation for $10 \mathrm{~min}$ at $95^{\circ} \mathrm{C}$, followed by 40 PCR cycles of denaturation at $95^{\circ} \mathrm{C}$ for $15 \mathrm{sec}$ and annealing or extension at $60^{\circ} \mathrm{C}$ for $1 \mathrm{~min}$. The threshold cycle $(\mathrm{Ct})$ value for each reaction was calculated and the relative quantitation ( $\Delta \Delta \mathrm{Ct}$ method) was carried out as described in our previous studies $(19,20)$. The amplified products were analyzed by $1.7 \%$ agarose gel electrophoresis and were visualized by ultraviolet illumination after staining with ethidium bromide.

Immunofluorescence. Cells were cultured on cover glasses and then were fixed in $4 \%$ paraformaldehyde in $0.1 \mathrm{M}$ phosphate buffer (PB). The specimens were washed in phosphatebuffered saline (PBS) and were blocked in $10 \%$ normal goat serum. They were then incubated with anti-human syndecan-1 antibody (1:500, Dako, Copenhagen, Denmark) at room temperature for $60 \mathrm{~min}$. After washing in PBS, Alexa488conjugated anti-mouse IgG (Molecular Probes, Eugene, OR, USA) was used as a secondary antibody and the specimens were observed using a fluorescence microscope (Axiophot2, Zeiss, Oberkochen, Germany).

siRNA transfection. In order to knock down syndecan-1 function in the cells, an siRNA insert of syndecan-1 was designed using a website named siRNA Target Finder (Ambion, Austin, TX, USA). Since the siRNA target sequence of syndecan-1 was 5'-AACTTCTCCGGCTCAGG TGCA-3', synthetic top strand oligonucleotide templates of the insert for syndecan-1 siRNA: 5'-CTTCTCCGGCTCAG GTGCATTCAAGAGATGCACCTGAGCCGGAGAAGTT TTTT-3' and the bottom strand oligonucleotide template: 5'-AATTAAAAAACTTCTCCGGCTCAGGTGCATCTCT TGAATGCACCTGAGCCGGAGAAGGGCC-3' were incubated with annealing buffer (TEN buffer: $10 \mathrm{mM}$ Tris- $\mathrm{HCl}$, $1 \mathrm{mM}$ EDTA, pH 7.6 and $100 \mathrm{mM} \mathrm{NaCl}$ ) at $95^{\circ} \mathrm{C}$ for $5 \mathrm{~min}$, then cooled to $37^{\circ} \mathrm{C}$ and incubated for $1 \mathrm{~h}$ at $37^{\circ} \mathrm{C}$. Synthetic oligonucleotides of syndecan-1 were inserted into the ApaI and EcoRI sites of the pSilencer ${ }^{\mathrm{TM}}$ 1.0-U6 vector (Ambion). The plasmid and pSilencer 1.0 Negative Control (Ambion) were transfected into the cells using the lipofection method (Effecten $^{\mathrm{TM}}$, Qiagen, Hilden, Germany) according to the manufacturer's protocol. Decreased expression of syndecan-1 in the cells was confirmed by RT-PCR.

Cell growth rate. The cells were seeded at $1.0 \times 10^{5}$ cells $/ \mathrm{ml}$ into $35-\mathrm{mm}$ plates. The cells were detached using $0.25 \%$ trypsin every $24 \mathrm{~h}$ and were counted using a Coulter Counter (Beckman Coulter, Fullerton, CA, USA). Results were analyzed and growth curves were plotted.

Invasion assay. The invasion assay was carried out according to our previous studies $(19,21)$. Aliquots of $1 \times 10^{5}$ cells were plated onto 6-well BioCoat ${ }^{\mathrm{TM}}$ Matrigel $^{\mathrm{TM}}$ Invasion Chambers (BD Biosciences, San Jose, CA, USA) and were cultured for $24 \mathrm{~h}$. Cells digested the Matrigel, enabling them to pass through the micro-pores in the gel, after which they were fixed and stained. The numbers of invasive cells were counted using a light microscope per $1 \mathrm{~mm}^{2}$ in the central area of the Matrigel. The assays were repeated three times and results are shown as mean $\pm \mathrm{SD}$.

\section{Results}

Expression of syndecan-1 mRNA in human oral carcinoma cell lines. To validate the high expression levels of syndecan- 1 in human oral cancer cell lines, QRT-PCR was carried out. Based on the $\Delta \Delta \mathrm{Ct}$ relative to $\mathrm{KB}$ cells, the relative expression levels of syndecan-1 mRNA in oral carcinoma cell lines were calculated. Several cell lines showed expression of syndecan-1 at high levels. In particular, syndecan-1 was expressed in Ca9-22 cells at a higher level (13.2-fold) than in KB cells (Fig. 1A). Moreover, relatively higher expression levels of syndecan-1 were seen in BSC-OF and in HSC3 cells (7.6-fold).

Immunofluorescence analysis showed that positive reactions for syndecan-1 were observed strongly at the cell membrane of Ca9-22 cells (Fig. 1B) while diffuse faint dot reactions were seen in $\mathrm{KB}$ cells (Fig. 1C). Based on those 


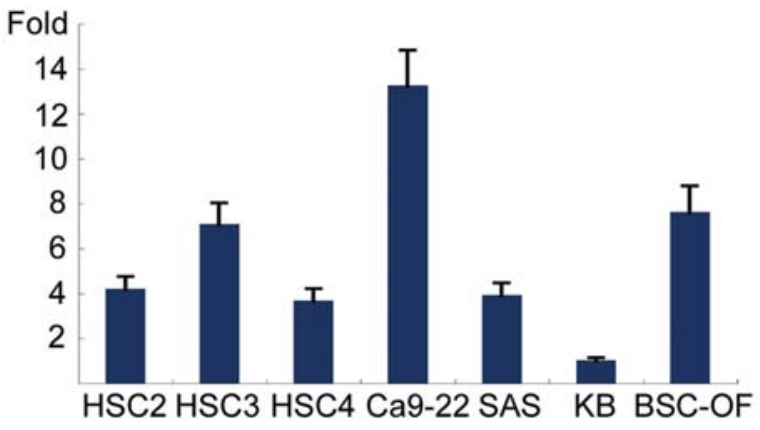

A

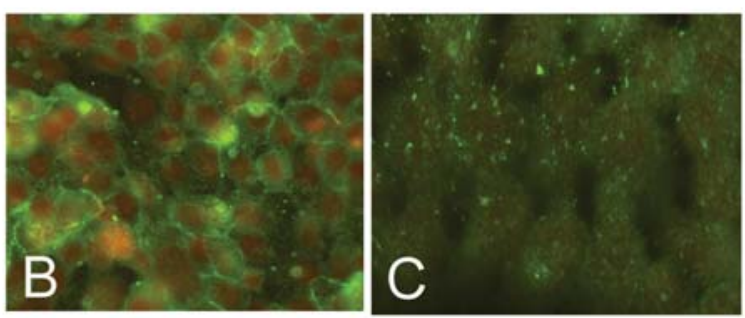

Figure 1. Expression of human syndecan-1 in oral carcinoma cells. (A) QRT-PCR analysis shows that syndecan-1 is expressed in Ca9-22 cells at a higher level (13.2-fold) than in KB cells. Moreover, a relatively higher expression level of syndecan-1 is seen in BSC-OF cells and in HSC3 cells (7.6-fold). The $\Delta \Delta \mathrm{Ct}$ relative to $\mathrm{KB}$ cells is considered as 1 . (B and $\mathrm{C}$ ) Immunofluorecence analysis shows that positive reactions for syndecan-1 are strongly observed at the cell membrane of Ca9-22 cells (B) while diffuse faint dot reactions are seen in $\mathrm{KB}$ cells $(\mathrm{C})$.
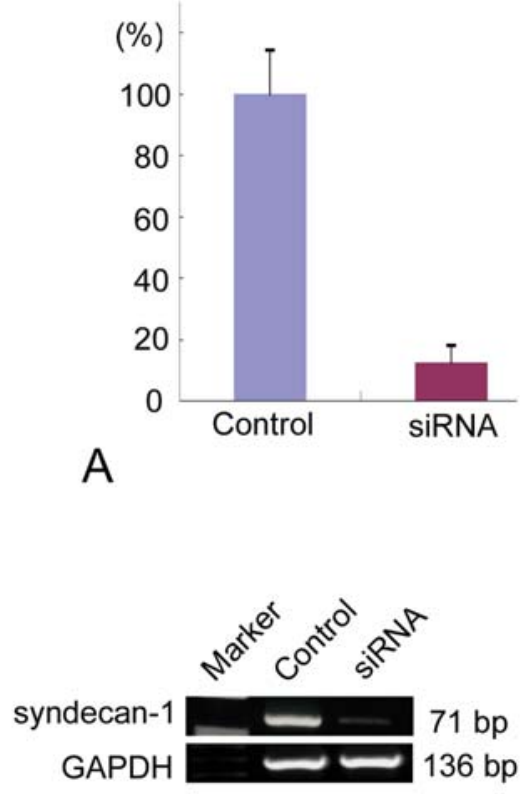

B

Figure 2. Efficiency of human syndecan-1 siRNA. (A) In order to characterize the effects of syndecan-1 siRNA, QRT-PCR analysis was performed on mRNAs from non-transfected (control) and from siRNA-transfected Ca9-22 cells. After $48 \mathrm{~h}$ incorporation, decreased expression (1/10-fold) of syndecan-1 was seen in the siRNA-transfected cells, suggesting that siRNA blocks syndecan-1 expression very efficiently in Ca9-22 cells. (B) Electrophoresis analysis confirming a decline in syndecan-1 in siRNA-transfected Ca9-22 cells.

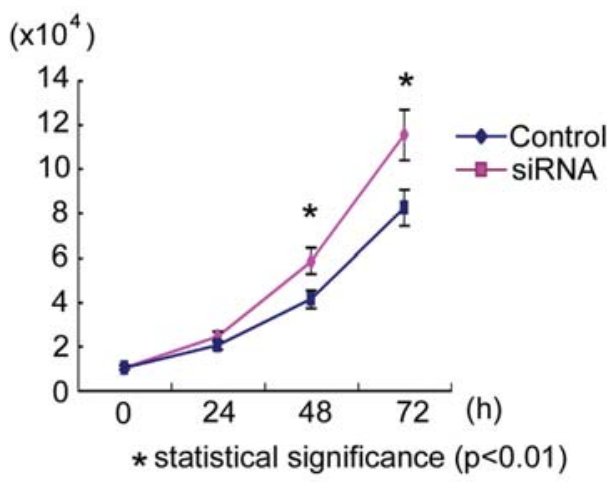

Figure 3. Cell growth rates. Ca9-22 cells transfected with syndecan-1 siRNA had increased growth. The growth rate of control cells was lower than the siRNA-treated cells at 48 and at $72 \mathrm{~h}$. The growth rates were significantly different between the siRNA and the control groups at 48 and at $72 \mathrm{~h}(\mathrm{p}<0.01)$.

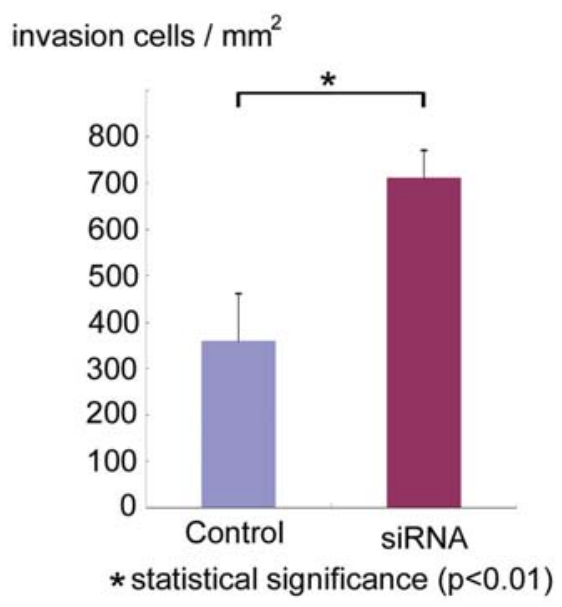

Figure 4. Invasion assay. The Matrigel assay was used to investigate the effects of syndecan- 1 on the invasive ability of Ca9-22 cells. The number of invading cells was significantly higher in the siRNA-transfected group $(\mathrm{p}<0.01)$.

QRT-PCR and immunofluorescence results, we used Ca9-22 cells as a model for high expression of syndecan-1 in this study.

Effects of human syndecan-1 siRNA. In order to characterize the effects of syndecan-1 siRNA, we carried out QRT-PCR analysis using mRNAs from non-transfected (control) and from transfected Ca9-22 cells. After 48 h of incorporation, decreased expression (1/10-fold) of syndecan- 1 was seen in the siRNA-transfected cells, suggesting that siRNA blocked syndecan-1 expression very efficiently in Ca9-22 cells (Fig. 2A). Electrophoretic analysis confirmed that a decline of syndecan-1 was observed in transfected Ca9-22 cells (Fig. 2B).

Cell growth. To examine whether syndecan-1 is associated with cell growth, the growth of siRNA-transfected cells and control cells was measured. Ca9-22 cells had increased growth after syndecan-1 siRNA transfection. The numbers of siRNA-transfected Ca9-22 cells and control cells at $48 \mathrm{~h}$ were $6.0 \pm 0.4 \times 10^{5}$ and $4.1 \pm 0.3 \times 10^{5}$ (average \pm SD), respectively and at $72 \mathrm{~h}$ were $11.8 \pm 1.4 \times 10^{5}$ and $8.1 \pm 0.5 \times 10^{5}$, 
respectively. The cell growth rate of control cells was lower than the siRNA-transfected cells at 48 and at $72 \mathrm{~h}$ (Fig. 3) and were significantly different at both time points $(\mathrm{p}<0.01)$.

Invasion assay. To examine the effect of syndecan- 1 on the invasive ability of Ca9-22 cells, a Matrigel assay was used. The numbers of invasive siRNA-transfected and control Ca9-22 cells were $718.4 \pm 64.7$ per $\mathrm{mm}^{2}$ and $378.8 \pm 102.1$ per $\mathrm{mm}^{2}$ (average $\pm \mathrm{SD}$ ), respectively, which was significantly higher ( $\mathrm{p}<0.01)$ (Fig. 4).

\section{Discussion}

Syndecan-1 has been reported to be a prognostic factor for tumor progression and survival in various types of malignant tumors, which suggests a close correlation of syndecan-1 expression with malignancy and metastasis $(16,22)$. In general, transformed cells are often characterized by an abundant secretion of syndecan-1, which results in metastasis formation $(23,24)$. Earlier studies associated syndecan-1 levels with prognosis and have suggested syndecan-1 as a candidate biomarker for the malignant potential of head and neck tumors (16). Our earlier study showed that syndecan-1 contributed to their malignant behavior including changes in growth and invasive ability (17). However, expression levels and function(s) of syndecan-1 in oral cancers have not been clarified, and therefore, we examined that in this study using siRNA to block syndecan-1 functions. Our results show that three oral cancer cell lines, Ca9-22, BSC-OF and HSC3, express syndecan-1 at high levels compared to $\mathrm{KB}$ cells. Ca9-22 cells are therefore a useful model for elucidating the function of syndecan-1 in oral cancers. Furthermore, our results show that the siRNA used in this study is specific and is effective for blocking syndecan-1 expression and thus will be helpful for analyzing the function(s) of syndecan-1 in oral cancer cells.

Our previous study showed that the reduction of immunoreactivity for syndecan-1 in oral squamous cell carcinoma cells was associated with tumor size, suggesting that syndecan-1 contributes to malignant behavior including changes in growth and invasive ability. Recent studies have shown that a reduction of syndecan- 1 expression was associated with proliferative activity (Ki-67 expression) (25). Furthermore, $\mathrm{Su}$ et al reported that shedding of syndecan-1 by stromal fibroblasts stimulated the proliferation of human breast cancer cells via activation of FGF2 (26). Our results show that the reduction of syndecan-1 function by siRNA leads to higher levels of cell proliferation, which suggests that syndecan-1 is directly associated with cell proliferation.

Cell migration has been reported to influence invasiveness and to be an important factor in the incidence of metastasis. Moreover, the invasive ability of tumors is closely related to the incidence of metastasis and the prognosis of the disease. As shown in previous studies, reduced expression of syndecan-1 correlates with metastasis of various tumors. There have been only a few studies that showed a correlation between syndecan-1 and invasion in oral cancers, but there has been no previous functional study of syndecan-1 using an oral cancer cell line. Therefore, we examined whether syndecan-1 was associated with the invasive ability of Ca9-22 cells. Our results show that invasiveness increased when syndecan-1 function was blocked in siRNA-transfected Ca9-22 cells. The expression of syndecan-1 is known to suppress the level of matrix metalloproteinase (MMP)-9 and to inhibit cell invasion into type I collagen $(27,28)$. Moreover, syndecan- 1 can be degraded by heparanase (29), and invasion is associated with MMPs (30) and heparanase activities (31). The syndecan-1 siRNA may induce MMPs and heparanase activity and thus reduce the expression of syndecan-1 in Ca9-22 cells .

\section{Acknowledgements}

This study was supported, in part, by the Japanese Ministry of Education, Culture, Sports, Science and Technology, Grant-inAid No. 14657489.

\section{References}

1. Greenlee RT, Hill-Harmon MB, Murray T and Thun M: 2001 Cancer statistics. CA Cancer J Clin 51: 15-36, 2001.

2. Takes RP, Baatenburg de Jong RJ, Schuuring E, Hermans J, Vis AA, Litvinov SV and van Krieken JH: Markers for assessment of nodal metastasis in laryngeal carcinoma. Arch Otolaryngol Head Neck Surg 123: 412-419, 1997.

3. Takes RP, Baatenburg De Jong RJ, Alles MJ, Meeuwis CA, Marres HA, Knegt PP, De La Riviere GB, De Wilde PC, Mooi WJ, Hermans J and Van Krieken JH: Markers for nodal metastasis in head and neck squamous cell cancer. Arch Otolaryngol Head Neck Surg 128: 512-518, 2002.

4. Alevizos I, Mahadevappa M, Zhang X, Ohyama H, Kohno Y, Posner M, Gallagher GT, Varvares M, Cohen D, Kim D, Kent R, Donoff RB, Todd R, Yung CM, Warrington JA and Wong DT: Oral cancer in vivo gene expression profiling assisted by laser capture microdissection and microarray analysis. Oncogene 20: 6196-6204, 2001

5. Macabeo-Ong M, Shiboski CH, Silverman S, Ginzinger DG, Dekker N, Wong DT and Jordan RC: Quantitative analysis of cathepsin L mRNA and protein expression during oral cancer progression. Oral Oncol 39: 638-647, 2003.

6. Roskelley CD, Srebrow A and Bissell MJ: A hierarchy of ECMmediated signalling regulates tissue-specific gene expression. Curr Opin Cell Biol 7: 736-747, 1995.

7. Inki P, Stenback F, Talve L and Jalkanen M: Immunohistochemical localization of syndecan in mouse skin tumors induced by UV irradiation. Loss of expression associated with malignant transformation. Am J Pathol 139: 1333-1340, 1991.

8. Lester BR and McCarthy JB: Tumor cell adhesion to the extracellular matrix and signal transduction mechanisms implicated in tumor cell motility, invasion and metastasis. Cancer Metastasis Rev 11: 31-44, 1992.

9. Bernfield M, Kokenyesi R, Kato M, Hinkes MT, Spring J, Gallo RL and Lose EJ: Biology of the syndecans: a family of transmembrane heparan sulfate proteoglycans. Annu Rev Cell Biol 8: 365-393, 1992.

10. Koda JE and Bernfield M: Heparan sulfate proteoglycans from mouse mammary epithelial cells. Basal extracellular proteoglycan binds specifically to native type I collagen fibrils. J Biol Chem 259: 11763-11770, 1984.

11. Saunders S and Bernfield M: Cell surface proteoglycan binds mouse mammary epithelial cells to fibronectin and behaves as a receptor for interstitial matrix. J Cell Biol 106: 423-430, 1988.

12. Inki P, Stenback F, Grenman S and Jalkanen M: Immunohistochemical localization of syndecan-1 in normal and pathological human uterine cervix. J Pathol 172: 349-355, 1994.

13. Rintala M, Inki P, Klemi P, Jalkanen M and Grenman S: Association of syndecan-1 with tumor grade and histology in primary invasive cervical carcinoma. Gynecol Oncol 75: 372-378, 1999.

14. Mikami S, Ohashi K, Usui Y, Nemoto T, Katsube K, Yanagishita M, Nakajima M, Nakamura K and Koike M: Loss of syndecan-1 and increased expression of heparanase in invasive esophageal carcinomas. Jpn J Cancer Res 92: 1062-1073, 2001. 
15. Inki P and Jalkanen M: The role of syndecan-1 in malignancies. Ann Med 28: 63-67, 1996.

16. Inki $\mathrm{P}$, Joensuu $\mathrm{H}$, Grenman R, Klemi $\mathrm{P}$ and Jalkanen $\mathrm{M}$ : Association between syndecan-1 expression and clinical outcome in squamous cell carcinoma of the head and neck. Br J Cancer 70: 319-323, 1994

17. Ro Y, Muramatsu T, Shima K, Yajima Y, Shibahara T, Noma H and Shimono M: Correlation between reduction of syndecan-1 expression and clinico-pathological parameters in squamous cell carcinoma of tongue. Int J Oral Maxillofac Surg 35: 252-277, 2006.

18. Abiko Y, Okumura K, Ohuchi T, Konishi T, Kanazawa M and Kaku T: Basaloid-squamous cell carcinoma of the floor of the mouth: characterization of a cell line. J Oral Pathol Med 26: 367-370, 1997.

19. Muramatsu T, Shima K, Ohta K, Kizaki H, Ro Y, Kohno Y, Abiko $\mathrm{Y}$ and Shimono M: Inhibition of osteopontin expression and function in oral cancer cell lines by antisense oligonucleotides. Cancer Lett 217: 87-95, 2005.

20. Ohtsuka W, Ohta K, Isshiki Y and Kizaki H: Quantitative analysis of osteopontin gene expression using a real time reverse transcription-polymerase chain reaction assay. J Hard Tissue Biol 9: 47-55, 2000

21. Shima K, Muramatsu T, Abiko Y, Yamaoka Y, Sasaki H and Shimono M: Connexin 43 transfection in basaloid squamous cell carcinoma cells. Oncol Rep 16: 285-288, 2006.

22. Kurokawa H, Zhang M, Matsumoto S, Yamashita Y, Tanaka T, Takamori K, Igawa K, Yoshida M, Fukuyama H, Takahashi T and Sakoda S: Reduced syndecan-1 expression is correlated with the histological grade of malignancy at the deep invasive front in oral squamous cell carcinoma. J Oral Pathol Med 35: 301-306, 2006.

23. Senger DR, Asch BB, Smith BD, Perruzzi CA and Dvorak HF: A secreted phosphoprotein marker for neoplastic transformation of both epithelial and fibroblastic cells. Nature 302: 714-715, 1983.
24. Senger DR and Perruzzi CA: Secreted phosphoprotein markers for neoplastic transformation of human epithelial and fibroblastic cells. Cancer Res 45: 5818-5823, 1985.

25. Kurokawa H, Matsumoto S, Murata T, Yamashita Y, Tomoyose T, Zhang M, Fukuyama $\mathrm{H}$ and Takahashi T: Immunohistochemical study of syndecan-1 down-regulation and the expression of $\mathrm{p} 53$ protein or Ki-67 antigen in oral leukoplakia with or without epithelial dysplasia. J Oral Pathol Med 32: 513-521, 2003.

26. Su G, Blaine SA, Qiao D and Friedl A: Shedding of syndecan-1 by stromal fibroblasts stimulates human breast cancer cell proliferation via FGF2 activation. J Biol Chem 282: 14906-14915, 2007.

27. Kaushal GP, Xiong X, Athota AB, Rozypal TL, Sanderson RD and Kelly T: Syndecan-1 expression suppresses the level of myeloma matrix metalloproteinase-9. Br J Haematol 104: 365-373, 1999.

28. Liebersbach BF and Sanderson RD: Expression of syndecan-1 inhibits cell invasion into type I collagen. J Biol Chem 269: 20013-20019, 1994.

29. Reiland J, Sanderson RD, Waguespack M, Barker SA, Long R, Carson DD and Marchetti D: Heparanase degrades syndecan-1 and perlecan heparan sulfate: functional implications for tumor cell invasion. J Biol Chem 279: 8047-8055, 2004

30. O-charoenrat P, Rhys-Evans PH and Eccles SA: Expression of matrix metalloproteinases and their inhibitors correlates with invasion and metastasis in squamous cell carcinoma of the head and neck. Arch Otolaryngol Head Neck Surg 127: 813-820, 2001.

31. Ikebe T, Shinohara M, Takeuchi H, Beppu M, Kurahara S, Nakamura S and Shirasuna K: Gelatinolytic activity of matrix metalloproteinase in tumor tissues correlates with the invasiveness of oral cancer. Clin Exp Metastasis 17: 315-323, 1999. 